\title{
Proteomic Analysis of Pathogen-Responsive Proteins from Maize Stem Apoplast Triggered by Fusarium Verticillioides
}

\author{
Hafiz Abdul Haseeb \\ Chinese Academy of Agricultural Sciences Institute of Food Science and Technology \\ Jun Zhang \\ Chinese Academy of Agricultural Sciences Institute of Food Science and Technology
}

\section{Yushuang Guo}

Key laboratory of Molecular Genetics, China National Tobacco Corporation

\section{Meixu Gao}

Chinese Academy of Agricultural Sciences Institute of Food Science and Technology

Wei GUO ( $\square$ guowei01@caas.cn )

Chinese Academy of Agricultural Sciences Institute of Food Science and Technology https://orcid.org/0000-0002-64116227

\section{Research article}

Keywords: Apoplastic proteins; Fusarium verticillioides; Plant defense response; Proteomic analysis

Posted Date: September 8th, 2020

DOI: https://doi.org/10.21203/rs.3.rs-60514/v1

License: (1) This work is licensed under a Creative Commons Attribution 4.0 International License. Read Full License 


\section{Abstract}

\section{Background:}

Plant apoplast is the frontline battlefield between the host and the invading pathogen. In response to the pathogen attack, a variety of defense-associated proteins are secreted by the host plant in the apoplast to impede the perceived attack. To better understand the plant response after Fusarium verticillioides attack, proteomic analyses of the maize apoplastic fluid was done using LC-MS/MS coupled with label-free quantification.

\section{Results:}

In total, 742 proteins responsive to the $F$. verticillioides infection were identified. Among them, 158 were differentially accumulated proteins (DAPs). Out of these 158 proteins, 35 were upregulated, and 18 were down-regulated, whereas, 65 and 40 unique proteins were identified from inoculated and un-inoculated plants, respectively. Enrichment analyses categorized the proteins into 4 pathways, and biosynthesis of amino acid was the prominent pathway followed by the metabolic pathways. Moreover, 86 DAPs were predicted as secretory proteins. The identified secreted proteins were related to a variety of pathways in defense responses, including cell redox homeostasis, cell wall modification, signal transduction, carbohydrate metabolism, and others.

\section{Conclusions:}

Our data suggested that the maize plants carried out a rigorous reprogramming of the proteins in the apoplastic region to cope with the attack of $F$. verticillioides.

\section{Background:}

Maize (Zea mays L.) is widely grown across the world because of its nutritional value and industrial use. The impact of fungal diseases on this vital crop is detrimental to sustainable food production and overall economic health, especially in the regions where maize is a staple food commodity. Among the several fungal diseases, Fusarium ear and stalk rot of maize, caused by Fusarium verticillioides (Saccardo) Nirenberg (synonym F. moniliforme Sheldon, teleomorph Gibberella moniliformis Wineland), has been of great importance because the disease is responsible for extensive yield losses[1]. The fungus can infect the maize crop during every stage of life, including seed, seedlings, mature plants, and even during the storage. $F$. verticillioides can also contaminate the maize by producing fumonisins and affect the quality of the production[2, 3]. Previous studies have shown that the contamination by the fumonisin was a reason for cancer in farm animals and humans[4,5]. In the Liaoning province of China, $F$. verticillioides was the predominant species causing the maize ear and stalk rot disease, and the fumonisins contamination as recorded as high as 81\%[6]. Similarly, another study published in 2013 stated that the level of fumonisins produced by F. verticillioides in maize gradually increased from the year 2011 to 2013 in the Hebei province of China, indicating that the special attention is needed for the contamination[7].

The apoplast consists of the cell wall and the intercellular spaces where the apoplastic fluid is present[8]. A vast diversity of proteins present in the apoplast has been reported to perform various developmental and physiological functions during growth, abiotic, and biotic stress responses, including the plant-pathogen interactions[9]. The apoplast has been considered as the first battleground during the interaction of the host plant with the invading pathogens. Due to the key events taking place in the apoplast, the overall cell defense system of the plant relies on the signals perceived in this region[ $[8,10]$. Since the apoplast is adjacent to the cell wall, it may act as a physical barrier to the invading pathogens[11]. The main events taking place at the apoplast include signal perception and transduction, reactive oxygen species (ROS) and redox modulation, cell wall modifications, and secretion of pathogenesis-related (PR) proteins and other defense-related proteins[12]. Therefore, the knowledge of the proteins found in the apoplast can provide valuable clues for the plant-pathogen interactions.

In the view of the advancements in plant proteomics technology, scientists have developed a better understanding of the proteins present in the specific tissues of the plants under particular conditions[13]. Various proteomic studies have been 
performed to find out the protein alterations in response to various abiotic and biotic conditions[8]. The proteomic studies during the plant-microbe interactions have been done in Arabidopsis[14], rice[15], and poplar[16]. In maize, cell suspension culture was used to study the extracellular proteomic response of the plant to the elicitor from F. verticillioides[17]. However, inplanta apoplastic proteomics response of maize, in response to the $F$. verticillioides attack, has not been reported previously. Here in this study, we have employed a common and powerful LC-MS/MS technique coupled with label-free quantification and identified the apoplastic proteins from maize in response to $F$. verticillioides infection. Furthermore, the identified proteins have also been bifurcated based on their secretory nature. The results obtained during this study will broaden our knowledge about the host plant responses towards the pathogenic fungi.

\section{Results}

Interaction of F. verticillioides with the maize roots

The effect of $F$. verticillioides on the maize root morphology was studied by using a hydroponic system (Fig. 1a). The maize seeds were first allowed to germinate on the germination papers already soaked in Hoagland's solution. After germination, the seeds were inoculated with the pathogen. The presence of the pathogen had a significant effect on the morphology of the roots of the seedlings. The inoculated roots were reduced in length as compared to the un-inoculated roots. Brown discoloration of the inoculated roots was also observed after the pathogen infection (Fig. 1b). Moreover, there was a noticeable difference in the total length of the inoculated and un-inoculated seedlings (Fig. 1b and c).

The root colonization by F. verticillioides was studied using a mixture of two staining solutions, i.e., WGA-Alexa Fluor ${ }^{\text {'m }} 488$ mixed with Propidium lodide (PI) or FM $^{\text {Tw }}$ 4-64 Dye. The fungal cell wall was stained with WGA-Alexa Fluor 488 (green colour), whereas the plant cell wall was stained with Propidium lodide (PI), and the plant plasma membrane was stained with $\mathrm{FM}^{\mathrm{Tm}}$ 4-64 Dye (Red colour). The pathogen was able to colonize all parts of the roots, especially close to the seed (Fig. 2a and b). The tips of the secondary roots and intercellular spaces (apoplast) were also colonized by F. verticillioides (Fig. 2c and d).

\section{Label-free Quantitative Proteomics Analysis Of Identified Maize Proteins}

A label-free quantitative proteomics approach was employed to analyze the apoplastic proteins secreted by the maize plant after $F$. verticillioides infection. After quality validation, 9071 peptides were identified. The detailed information of the identified peptides, including peptide sequence, peptide length, and others, have been mentioned as Additional file S1. A total of 742 proteins were identified from the maize plant that was present in all three biological replicates. The detailed information of the identified proteins has been mentioned as Additional file S2. To further understand the putative function, all the identified proteins were analyzed for their gene ontology (GO) terms, including biological process (BP), molecular function (MF), and cellular component (CC). The proteins showing fold change $\geq 2$ at $0.05 p$-value were considered as differentially expressed proteins. The upregulated, down-regulated and uniquely identified proteins between the inoculated and un-inoculated plants were collectively termed as differentially accumulated proteins (DAPs). Among the differentially accumulated proteins, 35 proteins were upregulated, whereas 18 proteins were down-regulated (Fig. 3). Besides, 65 and 40 proteins were uniquely identified in inoculated and un-inoculated plants, respectively (Additional file S3).

Gene Ontology (GO) terms representing all identified proteins and differentially accumulated proteins have been shown in Fig. 4a. The GO enrichment analysis for DAPs showed that the two most enriched BP were L-serine biosynthetic process and protein folding. Moreover, the most enriched MF was the cysteine-type endopeptidase inhibitor activity. For the CC category, protein complex, cytoplasm, extracellular region, and thylakoid lumen were significantly enriched (Fig. 4b). In addition to this, the enrichment of the KEGG enriched pathways resulted in the identification of biosynthesis of amino acids, protein processing in the endoplasmic reticulum, biosynthesis of secondary metabolites and metabolic pathways related to carbohydrates (Fig. 4c). 
Identification And Annotation Of Secreted Proteins

We extracted the apoplastic fluid from the stem of the maize plants infected by $F$. verticillioides. The proteins secreted by the maize plants were classified based on the conventional and unconventional secretion systems. During the conventional secretion system, the proteins are secreted through ER-Golgi mediated secretory pathways. However, in the unconventional secretion system, the ER-Golgi routes are bypassed. The differentially accumulated proteins (DAPs) were scanned for the presence of the signal peptide. Based on the scanning results, the identified secreted proteins were divided into two groups (1) Classical secreted proteins (predicted to follow the conventional secretion system), and (2) Non-classical secreted proteins (predicted to follow the unconventional secretion system), also known as leaderless secreted proteins (LSPs).

Among all the identified secreted proteins, more than $50 \%$ of proteins were predicted to have a signal peptide, hence followed the conventional secretion system. However, in un-inoculated plants, more proteins were secreted through the unconventional secretion system (Fig. 5). These findings confirmed that in response to the infection of $F$. verticillioides, maize plants activated both conventional and unconventional systems for the secretion of the apoplastic proteins. Based on the results, it can be speculated that the maize plant may have activated the ER-Golgi secretory pathway of protein secretion to activate the defense response.

The functional annotation of the secreted proteins was conducted by organizing the proteins based on their $\mathrm{GO}$ categories. For the biological process (BP) category, most of the secreted proteins were related to the cellular metabolic process, organic substance metabolic process, catabolic process and, response to stress. The pathogen infection has increased the secretion of the proteins associated with the catabolic process, organic substance metabolic process, nitrogen compound metabolic process, and response to stress. In contrast, the proteins related to cellular metabolic processes and biological regulation were reduced after infection of $F$. verticillioides. However, the secretion of 
proteins related to carbohydrate metabolic process, protein oligomerization, response to other organisms, and organic substance biosynthesis were induced as a result of pathogen presence (Fig. 6a). Similarly, for the molecular function (MF) category, a higher number of secreted proteins were related to ion binding, oxidoreductase activity, and hydrolase activity (Fig. 6b). However, their concentration was decreased after the pathogen attack. Besides, the number of proteins related to the hydrolase activity and antioxidant activity was increased as a result of pathogen infection. Moreover, the proteins related to the transferase activity, structural constituent of ribosomes, and enzyme regulator activity were only observed after the inoculation by $F$.

verticillioides. These results indicated that the maize plant changed the secretion of various proteins to deter the invasion of $F$. verticillioides, especially the proteins related to carbohydrate metabolism.

The identified proteins were also grouped based on their putative functions. The major protein groups were (a) proteins involved in redox homeostasis, (b) pathogenesis-related protein (PR), defense signaling, proteinase inhibitors, proteins related to glycosyl hydrolase $(\mathrm{GH})$ activity (responsible for carbohydrate degradation), (c) proteases/peptidases that are involved in breakage of the peptide bonds, (d) proteins involved in binding, proper protein folding, and protein stabilization. Besides, (e) protein involved in energy metabolism pathway, (f) transmembrane transport, and (g) some unknown function proteins were also identified (Table 1 and Additional file S1). 


\section{Table 1}

Apoplastic proteins secreted by maize (Zea mays) after 7 days of interaction with $F$. verticillioides.

Uniprot ID Protein Annotation

A0A1D6E530 Peroxidase

A0A1D6IMZ0 Peroxidase

B4FU88 Peroxidase

B4FH68 Peroxidase

B6THG0 Peroxidase

B6TLM5 Glutathione S-transferase

GSTU6

C4J9M7

2-Cys peroxiredoxin BAS1

chloroplastic

B4FN24

Peroxiredoxin, EC 1.11.1.15

A0A1D6I054 Uclacyanin-3

B6SH12 Pathogenesis-related protein3 (Win1)

A0A1D6KV12 Chitinase 1\& 2

COP3M6

A0A1D6HRU2 Pathogenesis-related maize seed protein

K7V329

Putative 0-glycosyl hydrolase superfamily protein (Basic endochitinase B \& C)
Protein Group

Proteins

involved in cell

redox

homeostasis
Microbe related, defense signaling, $\mathrm{GH}$ activity and, other stressrelated proteins 


\section{Uniprot ID}

Protein Annotation

Protein Group

Q2XXB3

Pathogenesis-related protein 6

K7VLF2 Cysteine proteinase inhibitor

Q30KW0

Cysteine proteinase inhibitor

COHEIO

Glyco_hydro_19_cat domaincontaining protein

B4G1J7

$\mathrm{X} 8$ domain-containing protein

B6U1 $\times 3$

PMR5N domain-containing protein

B4G233

Dirigent protein

B8A1R0

Putative beta-D-xylosidase 5

B6TU78

Glucan endo-1,3-betaglucosidase 7

B4FAQ3e

Polygalacturonase QRT3

COPNX6

Bowman-Birk type bran trypsin inhibitor

A0A1D6ES04 Caffeoyl-CoA 0methyltransferase 1

B4FJJ9

ATP-dependent(S)-NAD(P)H-

hydrate dehydratase, EC

4.2.1.93

Q49HE1

12-oxo-phytodienoic acid reductase 1

E7DDV3

Peroxisomal-CoA synthetase 
Uniprot ID

A0A1D6L886

K7UAX3

A0A1D6EAQ6

B4FVIO

B6SZ82

B6TIC7

COHHB1

COPKR9

COP559

B6U242

B6TJ90

B4FKH7

B4F7Z3

B4F976

B4F9E8

\section{Protein Annotation}

Protein Group
Germin-like protein subfamily

T member 1

Germin-like protein

Subtilisin-like protease SBT1.9

Aspartyl protease AED1

Subtilisin-like protease

Cysteine protease5 (Xylem

cysteine proteinase 2)

\section{Carboxypeptidase, EC 3.4.16.-}

Eukaryotic aspartyl protease family protein

Aspartyl protease AED1

OTU-like cysteine protease family protein

Histone H4

Cytochrome B5 isoform D

(Cytochrome b5)

LRR extensin-like protein 6

(Systemin receptor SR160)
Protease and peptidase proteins
Proteins

involved in protein

synthesis, protein binding, and proper protein folding

$17.4 \mathrm{kDa}$ class I heat shock protein 3

$17.4 \mathrm{kDa}$ class III heat shock protein 


\section{Uniprot ID}

B4F9R4

B6TGK1

K7UQT7

B4FRI1

A0A1D6PAA7

Protein Annotation

$60 S$ ribosomal protein L2 (60S

ribosomal protein L8-3)

Ribonuclease 2

Putative elongation factor 1gamma 2

Phosphoserine

aminotransferase, EC 2.6.1.52

Nascent polypeptideassociated complex alpha subunit-like protein
A0A1D6PYC3 Nascent polypeptide- associated complex alpha subunit-like protein 3

B6TF15

Xylose isomerase, EC 5.3.1.5

B6T7D4

Fructose-bisphosphate aldolase, EC 4.1.2.13

Q8S4W8

E9NQE4

Pyruvate decarboxylase

Carbonic anhydrase, EC 4.2.1.1

K7UAI4
A0A1D6N9M5 Early nodulin-like protein 3

Q9XF59
Beta-13-N-

Acetylglucosaminyltransferase family protein 


\section{B4G0J0}

\section{CFEM domain-containing protein}

\section{B4FJY0}

\section{Uncharacterized protein}

\section{Data Validation Through Rt-qpcr Assay}

Reverse transcription-quantitative polymerase chain reaction (RT-qPCR) was done to validate the protein quantification data. In total, 5 secreted proteins including pathogenesis-related 6 (PR6), bowman-birk type bran trypsin inhibitor (100284348), 12oxo-phytodienoic acid reductase (OPR4), Subtilisin-like protease SBT1.9 (103646447), and chitinase 1 (Zm00001d032947) were randomly selected to confirm the protein quantification results through gene expression analysis of the selected proteins. The expression levels of the genes were consistent with the protein quantification results (Fig. 7).

\section{Discussion}

The presence of the fungus induced two significant changes, including the retardation of growth and brown discoloration of the roots (Fig. 1). Besides, F. verticillioides was able to colonize all parts of the roots, including intercellular spaces (apoplast), the surface of the roots, and the tips of the secondary roots (Fig. 2). Retardation of growth is a common phenomenon after the pathogen attack[18]. The browning of the root tissues indicated the possible accumulation of phenolic compounds by the host, in response to the pathogen infection. The accumulation of the phenolic compounds is a primary stress response for the remodeling of the cell wall[19]. It can also be speculated that the fungus has secreted secondary metabolites such as melanin onto the root surface or may have blocked the oxygen for the plant, which causes the discoloration of the root cells. Therefore, we were interested to know the molecular strategy of the maize plant in the apoplastic region against the pathogen attack.

The vacuum infiltration-centrifugation (VIC) technique has been regarded as an efficient method of apoplastic fluid extraction and previously been successfully used to study the interaction of Arabidopsis[14], rice[20], and maize[21] with various pathogens. However, previous studies have reported the presence of proteins from other cellular compartments during the cell wall or apoplast preparations, using various extraction methods in different plant species [22-25]. In addition to the apoplastic proteins, many proteins related to the other compartments of the cell have also been identified in this study. The detection of a higher number of intracellular proteins indicated the disruption of the plasma membrane during the infiltration process [26]. It is well established that the plants use both conventional (ER-Golgi dependent) and unconventional (ER-Golgi independent) secretory pathways for the secretion of the apoplastic proteins[12, 27]. Generally, LSPs can account for more than $50 \%$ of all the proteins present in the plant secretome[8]. Surprisingly, after $F$. verticillioides attack, the maize plant increased the secretion of proteins through the conventional secretory pathway. After the pathogen attack, the number of conventionally secreted proteins was increased from $42-61 \%$, whereas the number of LSPs was decreased from $59-34 \%$. In a previous study, the number of LSPs was increased to $54 \%$ after Trichoderma virens attack the maize[21]. As high as $60 \%$ of proteins identified from the apoplast during the interaction of rice plants with Magnaporthe oryzae followed non-classical secretory pathways[15]. It was interesting to note that during this study, the number of LSPs was decreased in response to the pathogen attack. These results suggested that, in response to $F$. verticillioides, the maize plant may have switched to the classical secretory pathway for the secretion of the apoplastic proteins. 
Here, the expression of three peroxidases such as B4FU88, B4FH68, B6THG0 was upregulated after the pathogen attack. Besides, two peroxidase proteins (A0A1D6E530 and A0A1D6IMZ0) were unique to the apoplastic fluid of the inoculated plants. However, there was no effect of the pathogen infection on the concentration of one peroxidase protein (A0A1D6KK78) (Additional file S3). These findings indicated that the former two peroxidase proteins might be particularly crucial during the response of maize to $F$. verticillioides infection. Additionally, the other proteins related to Reactive oxygen species (ROS) activity, including glutathione s-transferase GSTU6 (B6TLM5), 2-cys peroxiredoxin BAS1 (C4J9M7) and peroxiredoxin (B4FN24) were also identified in response to the pathogen infection. Uclacyanin-3 (A0A1D6I054), which is implicated to play a role in the redox reaction during plant-pathogen interaction[28], was also induced by the pathogen attack. Defense-related proteins, including peroxidases, were induced in maize embryos, with varying resistance levels, after the infection of $F$. graminearum[29]. Reactive oxygen species (ROS) is a ubiquitous and complex early response to the pathogen attack by the plants, required for cell wall strengthening and also has a major role in regulating the programmed cell death[30]. The plant secretes peroxidases as a primary component of defense against the invading pathogens that play a key role in cell wall reinforcements and in producing reactive oxygen species (ROS)[31], and also help to the host plant to tolerate the oxidative stress[32]. It is well known that peroxidases are essential for the activation of ROS during PAMP-triggered immunity (PTI)[33]. The extent of ROS accumulation is governed by the antioxidant system of the plant, which maintains ROS balance for proper cellular functions[34] and the function of ROS as signaling molecules[35]. $\mathrm{H}_{2} \mathrm{O}_{2}$ is a major player in signal transduction for downstream defense responses[33]. For the signal specificity of the ROS, redox homeostasis is governed by the presence of low molecular weight antioxidants that absorb and buffer reductants and oxidants[33, 36]. The antioxidant status has pivotal importance during the response to the various environmental influencers, including the pathogen attack. Antioxidants status modulates the ROS balance and can set the benchmarks for general plant defense responses. In this study, the change in the number of antioxidant enzymes, after perceiving the pathogen, points out that the maize plant may have activated the other downstream defense pathways such as cell wall reconstruction and defense-related gene expression.

During the plant-pathogen interactions, induction of pathogenesis-related (PR) proteins has been regarded as a primary defense response that can also help to activate the downstream defense response. Generally, the PR proteins are induced in response to the signaling compounds such as jasmonic acid (JA), salicylic acid (SA), or ethylene[37]. During the interaction of maize with F. graminearum, the most abundant defense proteins were related to PR-10[38]. In this study, several proteins from PR and PR-like families have been identified. These proteins include win1 (B6SH12), chitinase 1 (A0A1D6KV12), basic endochitinase B (COP3M6), pathogenesis-related protein 1 (A0A1D6HRU2), pathogenesis-related protein 6 (Q2XXB3). Two cysteine proteinase inhibitors (K7VLF2, Q30KW0) and two proteins such as A0A1D6L886 and K7UAX3 related to the germinlike activity were also identified. Moreover, proteins belonging to the GH family, including K7V329, COHEI0, and B4G1J7, were induced after the $F$. verticillioides infection. The $\mathrm{GH}$ family proteins play a role in the maintenance of the plant cell wall. The induction of B6U1 $\times 3$ (PMR5N domain-containing protein)[39] and B4G233 (Dirigent protein)[40] further strengthened the idea of cell wall remodeling during the attack of the pathogen. Other defense-related proteins include putative beta-D-xylosidase 5 (B8A1R0), glucan endo-1,3 beta-glucosidase 7 (B6TU78), and polygalacturonase QRT3 (B4FAQ3) were also induced after the attack of the pathogen. The handling of the samples has caused the secretion of one bowman-birk type bran trypsin inhibitor protein (COPNX6), that has been secreted by the host plant in response to the mechanical damage[37]. However, the expression of this protein was down-regulated in the presence of $F$. verticillioides.

Moreover, caffeoyl-CoA o-methyltransferase 1 (A0A1D6ES04), which is involved in the production of phenolic compounds[41, 42], was also identified after the pathogen infection, which supports the notion that the change in root colour was due to the possible accumulation of phenolic compounds by the host plant. Another protein, ATP-dependent (S)-NAD(P)H-hydrate dehydratase (B4FJJ9), related to the repair of the metabolic pathways for stress adaption, was also identified after the infection of the pathogen[43]. In rice, the resistance to the Magnaporthe grisea was enhanced through the activation of pathogenicity related genes involved in the defense hormone Jasmonic Acid (JA) pathway[44]. Here, two proteins, including 12-oxo-phytodienoic acid reductase (Q49HE1) and peroxisomal-CoA synthetase (E7DDV3), are putatively related to the Jasmonic acid (JA) pathways, were also activated. The expression level of the former was increased, whereas the latter was detected only in response to the $F$. verticillioides attack. Both proteins have a major role in the conversion of JA precursor to JA 
after three rounds of beta-oxidation[45-47]. These results indicated that the maize plants might have activated the JA pathways to defend the invading pathogen.

Proteases/peptidases are the proteins secreted by the plants to cope with the invading pathogen by maintaining the cell wall. About $15 \%$ of the apoplastic proteins, secreted by the tobacco plant, were associated with the peptidase/protease family[48]. During the interaction of rice with $M$. oryzae, the rice plant induced 5 proteins related to proteases family[15]. Aspartic proteases have been reported to play a critical role in defense signaling in plants[49]. In this study, we have identified eight proteins belonging to the protease/peptidase family. These proteins include two subtilisin-like proteases, three aspartyl proteases, two cysteine protease family proteins, and one carboxypeptidase (Table 1). In addition to this, the proteins involved in binding (RNA-, heme-, and metal ion-binding), proper protein folding, and synthesis of other proteins were also observed during this study. These proteins include histone $\mathrm{H} 4$ (implicated to bind with other proteins during plant-pathogen interactions) [50], cytochrome B5 isoform D (involved in electron transfer activity during the lignin synthesis)[51], leucine-rich repeat family protein (involved in pathogen recognition)[52], two small heat shock proteins (sHSP) (required for proper folding of the proteins)[53].

Additionally, various ribosomal proteins (involved in protein synthesis, protein stabilization, and binding with other proteins) such as 60 S ribosomal protein L2, ribonuclease 2, putative elongation factor 1-gamma 2, phosphoserine aminotransferase, and two nascent polypeptide-associated (NAC) complex alpha subunit-like protein were also identified in this study. The ribosomal proteins play an important role in the defense of the host plants against various stimuli[8]. Moreover, the proteins involved in energy production pathways were also present in the apoplastic fluid of the maize. The proteins which are involved in the energy metabolism pathway include B6TF15, B6T7D4, Q8S4W8, K7UAI4, B6TF15 and E9NQE4, which is implicated to play a role in photosynthesis[54]. The proteins responsible for the transport of solutes and water, namely early nodulin-like protein 3 and aquaporin PIP1-2 and unknown functions including COP566 and B4G0J0, were also influenced in the presence of $F$. verticillioides.

\section{Conclusions}

This study clarifies that maize plants responded to $F$. verticillioides attack by secreting complex arsenals of proteins involved in a variety of pathways. The increase in peroxidase proteins after the pathogen attack indicated the activation of strong innate immune responses by the maize plant. The activation of PR proteins is an obvious and earliest response by the host to the pathogen attack. However, the involvement of carbohydrate metabolism, protein binding, protein stabilization, and other defense-related proteins indicated that the host plants make a rigorous protein reprogramming in the apoplastic region. The results presented here will provide a better understanding of the apoplastic immune response from the host plant in response to the pathogens.

\section{Methods}

\section{Plant and Fungal Materials}

The seeds of maize (B73), obtained from the Chinese Crop Germplasm Information System (CGRIS), Chinese Academy of Agricultural Sciences (CAAS), Beijing, were surface sterilized by dipping in $2 \%$ Sodium Hypochlorite (NaOCl) solution followed by treatment with $70 \%$ Ethanol for 5 minutes each and washed at least three times with sterilized water. Sterile germination papers ( $30 \times 45 \mathrm{~cm}$; Anchor Paper Company, MN, USA) were used for the germination of the seeds. The germination papers were soaked in sterile Hoagland's solution[55]. The seeds were allowed to germinate in a contamination-free and humiditycontrolled growth facility at $25^{\circ} \mathrm{C}$ with a 16 hours light/8 hours dark cycle and relative humidity of $80 \%$ for 72 hours. To apoplastic fluid was extracted from maize seedlings, which were grown in pots filled with solid substrate mixture and placed in a greenhouse at $25^{\circ} \mathrm{C}$ temperature and 16 hours light/8 hours dark period. The seedlings were inoculated at 4 leaf stage, and the apoplastic fluid was extracted at 7 days post-inoculation. F. verticillioides (LNF15-11) strain was maintained on potato dextrose agar at $25^{\circ} \mathrm{C}$ under 12 hours light/ 12 hours dark cycle for 7 days to induce conidiation. The conidia were collected 
by filtration using sterile water and filtered through a double layer of sterile Miracloth (Millipore Merck, MA, USA). All the experiments were repeated at least three times.

\section{Pathogen colonization studies of maize roots}

Sterilized maize seeds were allowed to germinate on the germination papers soaked in Hoagland's solution for 72 hours. After germination, the seeds were surface inoculated with the conidial suspension of $F$. verticillioides $(20 \mu l)$ at a concentration of $10^{6} \mathrm{conidia} / \mathrm{ml}$ and transferred to the $50 \mathrm{ml}$ tubes containing $30 \mathrm{ml}$ of sterile Hoagland's solution. Seedlings were supported by putting a piece of sterile cotton in $50 \mathrm{ml}$ tubes and incubated at $25^{\circ} \mathrm{C}$ in a humidity-controlled growth chamber. At 7 days post-inoculation, the seedlings were removed from the tubes, and roots were cut into small pieces of $2 \mathrm{~cm}$ length. Uninoculated seedlings were taken as control. The samples were divided into two groups: fresh samples either washed with phosphate-buffered saline (PBS) or fixed using freshly prepared ethanol: acetic acid (3: 1, v/v) solution. Subsequently, the samples were stained using two different staining solution mixtures: for fresh tissues, we used a combination of wheat germ agglutinin WGA-Alexa Fluor ${ }^{\mathrm{TM}} 488$ (Thermo Fisher Scientific, Shanghai, China) mixed with $\mathrm{FM}^{\mathrm{TM}}$ 4-64 dye (Thermo Fisher Scientific, Shanghai, China). The fixed tissues were stained by using a mixture prepared by WGA-Alexa Fluor ${ }^{\mathrm{TM}} 488$ and propidium iodide (PI) (Sigma-Aldrich, Beijing, China). The fungal hyphae (Green Channel) was stained with WGA-Alexa Fluor ${ }^{\mathrm{TM}}$ 488, whereas the plant tissues (Red Channel) were stained with PI (for cell wall staining) or FM ${ }^{\mathrm{TM}}$ 4-64 dye (for cell membrane staining)[56, 57]. For fresh plant tissues, the samples were washed with PBS solution and subsequently treated with the mixture of the staining solution, containing $10 \mu \mathrm{g} / \mathrm{ml} \mathrm{FM}^{\mathrm{TM}} 4-64$ dye, $10 \mu \mathrm{g} / \mathrm{ml} \mathrm{WGA-Alexa}$ Fluor $^{\mathrm{TM}} 488$ and $0.02 \%$ Tween 20 in $1 \mathrm{X}$ PBS, twice for 15 minutes. The plant tissues, already fixed in ethanol: acetic acid solution (3: $1 \mathrm{v} / \mathrm{v})$, were treated with 10 $\% \mathrm{KOH}$ solution for 4 hours at $95^{\circ} \mathrm{C}$ followed by submersion in PBS for 1 hour. The samples were infiltrated with the staining solution mentioned above after $\mathrm{FM}^{\mathrm{TM}} 4-64^{\mathrm{M}}$ dye was replaced with $\mathrm{PI}(20 \mu \mathrm{g} / \mathrm{mL})$. The stained samples were stored in $1 \mathrm{xPBS}$ and placed at $4{ }^{\circ} \mathrm{C}$ in darkness. The stained samples were observed and photographed with the help of a Leica DM2500 microscope (Leica microsystems Inc., IL, USA).

\section{Isolation of apoplastic proteins}

For the extraction of apoplastic fluid, the stem of the maize plants was cut into small sections $(5 \mathrm{~cm})$ using a sterile razor blade. Three replicates were used for each condition: inoculated and un-inoculated plants at 7 days post-inoculation. The apoplastic fluid was collected using the vacuum infiltration-centrifugation (VIC) methodology with slight modifications[58]. Briefly, the samples were washed using sterile water to remove any contamination from the surface and dried by gently blotting with tissue paper. The weight of the sample was measured, and the samples were then placed in a $20 \mathrm{ml}$ syringe and filled with distilled water. The air in the syringe was removed by pushing the plunger. After that, the tip of the syringe was covered with a piece of parafilm, and negative pressure was generated by pulling the plunger. Then the plunger was carefully released to avoid any cell lysis and cytoplasmic contamination. Now the syringe was unplugged to eject any air inside and replugged. Then a modest positive pressure was created inside the syringe by pressing the plunger carefully. The process was repeated until the whole plant tissue was infiltrated. The sample was removed from the syringe and gently blotted with the piece of absorbent paper to remove the liquid outside the surface of the samples. The sample was weighed again, and approximate volume was calculated by the difference in weight before and after the infiltration. The samples were placed in a $20 \mathrm{ml}$ syringe without plunger and inserted into a $50 \mathrm{ml}$ centrifuge tube, and centrifuged at $2000 \times \mathrm{g}$ for 15 minutes at $4{ }^{\circ} \mathrm{C}$ (Eppendorf, Hamburg, Germany). The harvested apoplastic fluid was further filtered through a cellulose acetate membrane $(0.22 \mu \mathrm{m}$ pore size) to ensure the removal of any cells or particulate matter in the fluid. The apoplastic fluids from uninoculated and inoculated plants were concentrated by freeze-drying (Thermo Fisher Scientific, USA), and rehydration of the samples was achieved by adding a $20 \mu \mathrm{l}$ buffer solution ( $25 \mathrm{mM}$ Tris- $\mathrm{HCL}$ and $100 \mathrm{mM} \mathrm{NaCl}, \mathrm{pH}=7.4)$. The samples were stored at $-80^{\circ} \mathrm{C}$ until the next use.

\section{Protein Digestion}


The protein sample for each treatment was mixed with a lysis buffer containing 4\% SDS, $100 \mathrm{mM}$ Tris-HCL, and $1 \mathrm{mM} \mathrm{DTT} \mathrm{(pH}$ 7.6) (Bio-Rad, USA) and boiled for 15 minutes. The debris was removed by centrifugation at $14000 \times \mathrm{g}$ for 40 minutes. After centrifugation, the supernatant was retained and quantified by the help of the BCA Protein Assay Kit (Bio-Rad, Beijing, China). The protein solution was added with $30 \mu \mathrm{l} \mathrm{SDT}$ buffer containing 4\% SDS, 150mM Tris-HCL and 100mM DTT (pH=8.0) (BioRad, USA). The sample volume was reduced by ultrafiltration (Microcon Units, $10 \mathrm{kD}$ ) after adding UA buffer (8 M Urea, $150 \mathrm{mM}$ Tris-HCL, $\mathrm{pH}=8.0$ ) to the samples. For alkylation, the samples were treated by $100 \mu$ iodoacetamide and were placed in complete darkness for 30 minutes at room temperature. The filters were washed with $100 \mu \mathrm{UA}$ buffer three times, followed by washing with $100 \mu \mathrm{l}$ of $25 \mathrm{mM}$ ammonium bicarbonate $\left(\mathrm{NH}_{4} \mathrm{HCO}_{3}\right)$. Finally, the protein suspension was diluted by adding 40 $\mu \mathrm{l}$ of $25 \mathrm{mM} \mathrm{NH}_{4} \mathrm{HCO}_{3}$ buffer and digested by adding trypsin (Promega, Madison, USA). The sample to trypsin mass ratio was adjusted as 50:1 for the first round of digestion at $37^{\circ} \mathrm{C}$ overnight, and 100:1 for the second round of digestion for 4 hours. The resulting peptides were collected by filtration. About $200 \mu \mathrm{g}$ of each protein sample was digested by trypsin. The peptides for each sample were desalted using Empore C18 solid-phase extraction column (Sigma-Aldrich, Beijing, China) and concentrated by vacuum centrifugation. The resulting peptides were reconstituted in $40 \mu \mathrm{l}$ of $0.1 \%(\mathrm{v} / \mathrm{v})$ of formic acid before analysis.

\section{HPLC and LC-MS/MS Analysis}

The HPLC and LC-MS/MS analysis were done by Shanghai Applied Protein Biotechnology, Ltd. Shanghai, China. Briefly, the peptides mixture was added to the buffer $A(0.1 \%$ Formic acid) and loaded onto a C18 trap column (Thermo Scientific Acclaim PepMap100, $100 \mu \mathrm{m} \times 2 \mathrm{~cm}$, nanoViper C18, $3 \mu \mathrm{m}, 100 \AA$ ). The reverse-phase trap column was connected to the C18 analytical column (Thermo scientific EASY column, $10 \mathrm{~cm}$, ID $75 \mu \mathrm{m}, 3 \mu \mathrm{m}, \mathrm{C} 18-\mathrm{A} 2)$. For the separation of peptides, a linear gradient of

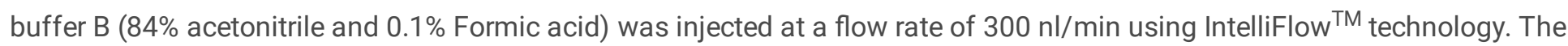
time for the linear gradient of buffer B was set to 120 minutes ( $0-55 \%$ for $110 \mathrm{~min}, 55-100 \%$ for $5 \mathrm{~min}$, hold in $100 \%$ for $5 \mathrm{~min}$ ).

For LC-MS/MS analysis, the Q Exactive ${ }^{\mathrm{TM}}$ mass spectrometer coupled with Easy $\mathrm{nLC}$ Liquid Chromatograph (Thermo Fisher Scientific Co. Ltd., Shanghai, China) was used for 120 minutes. The instrument was operated on positive ion mode and run with peptide recognition enabled. MS data was acquired by series of cyclic scans at a high resolution of 70,000 using a datadependent method dynamically choosing the most abundant precursor ions from the survey scans (300-1800 m/z) followed by scans at a relatively low resolution of 17,500 at $200 \mathrm{~m} / \mathrm{z}$. The survey scan width was set as $2 \mathrm{~m} / \mathrm{z}$. The automatic gain control (AGC) target was set to $3 \mathrm{e} 6$, whereas the maximum time for injection was set to $10 \mathrm{~ms}$. The dynamic exclusion duration was set as $40 \mathrm{sec}$. The normalized collision energy was $30 \mathrm{eV}$, and the underfill ratio was defined as $0.1 \%$. The underfill ratio specifies the minimum percentage of the target value to reach the maximum fill time.

\section{Database search and label-free quantification analysis}

The MS data were searched against the Maize Uniprot proteome database (https://www.uniprot.org/proteomes/UP000007305), including other contaminants (total number of entries 132460) using Andromeda connected with the MaxQuant Software version 1.3.0.5 (Max Plank Institute of Biochemistry, Martinized, Germany) using the default parameters. To quantify the proteins, Carbamidomethylation was set as a fixed modification, whereas the oxidation as a variable modification. A mass error of 20 ppm was allowed with 2 min retention time for shift tolerance. False Discovery Rate (FDR) threshold for proteins and peptides was less than $1 \%$, the peptides having less than 7 amino acids were not included. Besides, proteins having unique peptides were considered for quantification.

\section{Protein annotation}

For protein annotation, the Blast2GO bioinformatics platform was used to search the sequences. For pathways analysis, the online Kyoto Encyclopedia of Genes and Genomes (KEGG) (https://www.genome.jp/kegg) database was searched, and the proteins were mapped for KEGG pathways. Subsequently, the corresponding GO terms and KEGG pathways were extracted. The secreted proteins were identified using different online servers including SignalP (http://www.cbs.dtu.dk/services/SignalP/)[59], TMHMM (http://www.cbs.dtu.dk/services/TMHMM/)[60]. For subcellular 
localization, WolfpSort (https://wolfpsort.hgc.jp/)[61] and TargetP (http://www.cbs.dtu.dk/services/TargetP/)[62] were used, whereas, SecretomeP (http://www.cbs.dtu.dk/services/SecretomeP/)[63] was used to predict the leaderless secretory proteins (Additional file S3).

\section{Reverse transcription-quantitative PCR validation (RT-qPCR)}

To validate the protein quantification results, RNA from each sample was extracted using the commercial RNA extraction Kit (Easy Spin, NBFB, Beijing, China) by following the manufacturer's instructions. The first-strand cDNA was synthesized from 3 $\mu \mathrm{g}$ of total RNA with the help of a commercial cDNA synthesis kit (Takara, Dalian, China) according to the manufacturer's instructions. RT-qPCR was done using the SYBR Green kit (NovoStart ${ }^{\circledR}$ SYBR qPCR SuperMix Plus) on QuantStudio (TM) 6 Flex System (Thermo Fisher Scientific, Shanghai, China). The experiment was conducted in triplicate. The maize actin gene was used as an internal standard to calculate relative fold-changes based on comparative cycle threshold $\left(2^{-\Delta \Delta C t}\right)$ values. The primers were designed using the DNASTAR laser gene version 7.5. (Additional file S4).

\section{Abbreviations}

DAPs

Differentially accumulated proteins; VIC:Vacuum Infiltration-Centrifugation; FDR:False discovery rate; GO:Gene Ontology; LCMS/MS:Liquid Chromatography-Mass Spectrometry; HPLC:High-Performance Liquid Chromatography; KEGG:Kyoto Encyclopedia of Genes and Genomes; AGC:Automatic Gain Control; RT-qPCR:Reverse transcription-quantitative polymerase chain reaction

\section{Declarations}

\section{Ethics approval and consent to participate}

We use plant materials and did not employed transgenic technology. It does not require ethical approval.

\section{Consent for publication}

Not applicable.

\section{Availability of data and materials}

The datasets supporting the conclusions of this article are included within the article and its additional files.

\section{Competing interests}

The authors declare no competing interests.

\section{Funding}

This research work was partially supported by the National Key Research and Development Program of China (2017YFC1600903 and 2016YFD040015), National Natural Science Foundation of China (No. 31670143), Natural Science Foundation of Beijing Municipality (No. 6192023), Agricultural Science and Technology Program for Innovation Team on Prevention and Control of Mycotoxin Contamination in Agro-products (CAAS-ASTIP-2020-IFST-03). Hafiz Abdul Haseeb received the scholarship grant from China Scholarship Council (CSC) (No. 2017GXZ022555). All these funders do not play roles in the design of the study, analysis, and interpretation of data and writing of the manuscript, but provide the financial assistance for the project.

\section{Authors' contributions}


WG conceived and designed the experiments. HAH and JZ performed the experiments. JZ, HAH, and WG analyzed the data and wrote the manuscript. WG, YSG, and MXG coordinated the project. The final manuscript was read and approved by all the authors.

\section{Acknowledgments}

The authors thank the Shanghai Applied Protein Technology Co. Ltd for its technical support.

\section{Authors' information}

\section{Affiliations}

Institute of Food Science and Technology, Chinese Academy of Agricultural Sciences/Key Laboratory of Agro-products Quality and Safety Control in Storage and Transport Process, Ministry of Agriculture and Rural Affairs, Beijing 100193, P.R. China

Hafiz Abdul Haseeb, Jun Zhang, Meixu Gao, Wei Guo

Key Laboratory of Molecular Genetics, China National Tobacco Corporation, Guizhou Institute of Tobacco Science, Guiyang, Guizhou 550083, P.R. China

Yushuang Guo

\section{Corresponding author}

Correspondence to Wei Guo.

\section{References}

1. Aoki T, O'Donnell K, Geiser DM. Systematics of key phytopathogenic Fusarium species: current status and future challenges. J Gen Plant Pathol. 2014;80:189-201. doi:10.1007/s10327-014-0509-3.

2. Munkvold GP. Epidemiology of Fusarium diseases and their mycotoxins in maize ears. Eur J Plant Pathol. 2003;109:70513.

3. Fandohan K, Hell WFO, Marasas MJ. Wingfield. Infection of maize by Fusarium species and contamination with fumonisin in africa. Afr J Biotechnol. 2003;2:570-9.

4. Marasas WFO. Fumonisins. Their implications for human and animal health. Nat Toxins. 1995;3:193-8.

5. Stockmann-Juvala H, Savolainen K. A review of the toxic effects and mechanisms of action of fumonisin B 1. Hum Exper Toxicol. 2008;27:799-809.

6. Fu M, Li R, Guo C, Pang M, Liu Y, Dong J. Natural incidence of Fusarium species and fumonisins B1 and B2 associated with maize kernels from nine provinces in China in 2012. Food Addit Contam - Part A Chem Anal Control Expo Risk Assess. 2015;32:503-11. doi:10.1080/19440049.2014.976846.

7. Li R, Guo C, Zhang Q, Pang M, Liu Y, Dong J. Fumonisins B. and B 2 in maize harvested in Hebei province, China, during 2011-2013. Food Addit Contam Part B. 2015;1:8:1-6. doi:10.1080/19393210.2014.940401.

8. Agrawal GK, Jwa NS, Lebrun MH, Job D, Rakwal R. Plant secretome: Unlocking secrets of the secreted proteins. Proteomics. 2010;10:799-827.

9. Ellis JG, Dodds PN, Lawrence GJ. The role of secreted proteins in diseases of plants caused by rust, powdery mildew and smut fungi. Curr Opin Microbiol. 2007;10:326-31. doi:10.1016/j.mib.2007.05.015.

10. Doehlemann G, Hemetsberger C. Apoplastic immunity and its suppression by filamentous plant pathogens. New Phyto. 2013;198:1001-16. doi:10.1111/nph.12277.

11. Hückelhoven R. Cell Wall-Associated Mechanisms of Disease Resistance and Susceptibility. Annu Rev Phytopathol. 2007;45:101-27. doi:10.1146/annurev.phyto.45.062806.094325. 
12. Delaunois B, Jeandet P, Clément C, Baillieul F, Dorey S, Cordelier S. Uncovering plant-pathogen crosstalk through apoplastic proteomic studies. Front Plant Sci. 2014;5:JUN.

13. $10.1385 / 1597452270$

Mechin V, Damerval C, Zivy M, Thiellement H. Methods in Molecular Biology, vol. 355, Plant Prot Meth Proto. Humana Press; 2006. doi:10.1385/1597452270.

14. Floerl S, Majcherczyk A, Possienke M, Feussner K, Tappe H, Gatz C, et al. Verticillium longisporum infection affects the leaf apoplastic proteome, metabolome, and cell wall properties in Arabidopsis thaliana. PLoS One. 2012;7:e31435. doi:10.1371/journal.pone.0031435.

15. Kim SG, Wang Y, Lee KH, Park ZY, Park J, Wu J, et al. In-depth insight into in vivo apoplastic secretome of riceMagnaporthe oryzae interaction. J Proteomics. 2013;78:58-71. doi:10.1016/j.jprot.2012.10.029.

16. Pechanova O, Hsu CY, Adams JP, Pechan T, Vandervelde L, Drnevich J, et al. Apoplast proteome reveals that extracellular matrix contributes to multistress response in poplar. BMC Genom. 2010;11:674. doi:10.1186/1471-2164-11-674.

17. Chivasa S, Simon WJ, Yu X-L, Yalpani N, Slabas AR. Pathogen elicitor-induced changes in the maize extracellular matrix proteome. Proteomics. 2005;5:4894-904. doi:10.1002/pmic.200500047.

18. Huot B, Yao J, Montgomery BL, He SY. Growth-defense tradeoffs in plants: A balancing act to optimize fitness. Mol Plant. 2014;7:1267-87. doi:10.1093/mp/ssu049.

19. Beckman $\mathrm{CH}$. Phenolic-storing cells: Keys to programmed cell death and periderm formation in wilt disease resistance and in general defense responses in plants? Physiol Mol Plant Pathol. 2000;57:101-10.

20. Shenton MR, Berberich T, Kamo M, Yamashita T, Taira H, Terauchi R. Use of intercellular washing fluid to investigate the secreted proteome of the rice-Magnaporthe interaction. J Plant Res. 2012;125:311-6.

21. Nogueira-Lopez G, Greenwood DR, Middleditch M, Winefield C, Eaton C, Steyaert JM, et al. The apoplastic secretome of trichoderma virens during interaction with maize roots shows an inhibition of plant defense and scavenging oxidative stress secreted proteins. Front Plant Sci. 2018;9 April:1-23.

22. Irshad M, Canut H, Borderies G, Pont-Lezica R, Jamet $E$. A new picture of cell wall protein dynamics in elongating cells of Arabidopsis thaliana: Confirmed actors and newcomers. BMC Plant Biol. 2008;8:94. doi:10.1186/1471-2229-8-94.

23. Gokulakannan GG, Niehaus K. Characterization of the Medicago truncatula cell wall proteome in cell suspension culture upon elicitation and suppression of plant defense. J Plant Physiol. 2010;167:1533-41. doi:10.1016/j.jplph.2010.06.023.

24. Stephen Chivasa, Bongani K Ndimba, William J Simon, Duncan Robertson, Xiao-Lan Yu, J Paul Knox, et al. Proteomic analysis of the Arabidopsis thaliana cell wall. Electrophoresis. 2002;23. doi:10.1002/1522-

2683(200206)23:11<1754::AID-ELPS1754>3.0.CO;2-E.

25. Borderies G, Jamet E, Lafitte C, Rossignol M, Jauneau A, Boduart G, et al. Proteomics of loosely bound cell wall proteins of Arabidopsis thaliana cell suspension cultures: A critical analysis. Electrophoresis. 2003;24:3421-32.

doi:10.1002/elps.200305608.

26. Witzel K, Shahzad M, Matros A, Mock HP, Mühling KH. Comparative evaluation of extraction methods for apoplastic proteins from maize leaves. Plant Meth. 2011;7:1-11.

27. Yadav N, Khurana SMP, Yadav DK. Plant secretomics: Unique initiatives. In: PlantOmics: Omi Plant Sci. Spring India; 2015. p. 385-412.

28. Nersissian AM, Immoos C, Hill MG, Hart PJ, Williams G, Herrmann RG, et al. Uclacyanins, stellacyanins, and plantacyanins are distinct subfamilies of phytocyanins: Plant-specific mononuclear blue copper proteins. Protein Sci. 1998;7:1915-29.

29. Reid LM, Altosaar I. Host defense responses of CO441 and CL30 maize lines to Fusarium graminearum analyzed by comparative label-free quantitative proteomics. bioRxiv. 2019;:700542.

30. Bolwell GP. The apoplastic oxidative burst in response to biotic stress in plants: a three-component system. J Exp Bot. 2002;53:1367-76. doi:10.1093/jexbot/53.372.1367.

31. Mehdy MC. Active oxygen species in plant defense against pathogens. Plant Physio. 1994;105:467-72.

Page 17/26 
32. Yoshimura K, Miyao K, Gaber A, Takeda T, Kanaboshi H, Miyasaka H, et al. Enhancement of stress tolerance in transgenic tobacco plants overexpressing Chlamydomonas glutathione peroxidase in chloroplasts or cytosol. Plant J. 2004;37:2133.

33. Camejo D, Guzmán-Cedeño Á, Moreno A. Reactive oxygen species, essential molecules, during plant-pathogen interactions. Plant Physiol Biochem. 2016;103 March:10-23. doi:10.1016/j.plaphy.2016.02.035.

34. Baxter A, Mittler R, Suzuki N. ROS as key players in plant stress signaling. J Exp Bot. 2014;65:1229-40.

35. Qi J, Song CP, Wang B, Zhou J, Kangasjärvi J, Zhu JK, et al. Reactive oxygen species signaling and stomatal movement in plant responses to drought stress and pathogen attack. J Integr Plant Biol. 2018;60:805-26.

36. Foyer $\mathrm{CH}$, Noctor $\mathrm{G}$. Redox homeostasis and antioxidant signaling: A metabolic interface between stress perception and physiological responses. Plant Cell. 2005;17:1866-75.

37. van Loon LC, Rep M, Pieterse CMJ. Significance of Inducible Defense-related Proteins in Infected Plants. Annu Rev Phytopathol. 2006;44:135-62. doi:10.1146/annurev.phyto.44.070505.143425.

38. Mohammadi M, Anoop V, Gleddie S, Harris LJ. Proteomic profiling of two maize inbreds during early gibberella ear rot infection. Proteomics. 2011;11:3675-84. doi:10.1002/pmic.201100177.

39. Vogel JP, Raab TK, Somerville CR, Somerville SC. Mutations in PMR5 result in powdery mildew resistance and altered cell wall composition. Plant J. 2004;40:968-78. doi:10.1111/j.1365-313X.2004.02264.x.

40. Paniagua C, Bilkova A, Jackson P, Dabravolski S, Riber W, Didi V, et al. Dirigent proteins in plants: modulating cell wall metabolism during abiotic and biotic stress exposure. J exper bot. 2017;68:3287-301.

41. Chen C, Meyermans H, Burggraeve B, De Rycke RM, Inoue K, De Vleesschauwer V, et al. Cell-specific and conditional expression of caffeoyl-coenzyme A-3-O-methyltransferase in poplar. Plant Physiol. 2000;123:853-67.

42. Mandal SM, Chakraborty D, Dey S. Phenolic acids act as signaling molecules in plant-microbe symbioses. Plant Signal Behav. 2010;5:359-68.

43. Petrovova M, Tkadlec J, Dvoracek L, Streitova E, Licha I. NAD(P)H-hydrate dehydratase- A metabolic repair enzyme and its role in Bacillus subtilis stress adaptation. PLoS One. 2014;9.

44. Mei C, Qi M, Sheng G, Yang Y. Inducible overexpression of a rice allene oxide synthase gene increases the endogenous jasmonic acid level, PR gene expression, and host resistance to fungal infection. Mol Plant-Microbe Interact. 2006;19:1127-37.

45. Koo AJK, Howe GA. Role of peroxisomal $\beta$-oxidation in the production of plant signaling compounds. Plant Signal Behav. 2007;2:20-2.

46. Schneider K, Kienow L, Schmelzer E, Colby T, Bartsch M, Miersch O, et al. A new type of peroxisomal Acyl-coenzyme a synthetase from Arabidopsis thaliana has the catalytic capacity to activate biosynthetic precursors of jasmonic acid. $J$ Biol Chem. 2005;280:13962-72.

47. Koo AJK, Hoo SC, Kobayashi Y, Howe GA. Identification of a peroxisomal acyl-activating enzyme involved in the biosynthesis of jasmonic acid in Arabidopsis. J Biol Chem. 2006;281:33511-20.

48. Goulet C, Goulet C, Goulet MC, Michaud D. 2-DE proteome maps for the leaf apoplast of Nicotiana benthamiana. Proteomics. 2010;10:2536-44.

49. Xia Y, Suzuki H, Borevitz J, Blount J, Guo Z, Patel K, et al. An extracellular aspartic protease functions in Arabidopsis disease resistance signaling. EMBO J. 2004;23:980-8.

50. Ramirez-Prado JS, Piquerez SJM, Bendahmane A, Hirt H, Raynaud C, Benhamed M. Modify the histone to win the battle: Chromatin dynamics in plant-pathogen interactions. Front Plant Sci. 2018;9.

51. Gou M, Yang X, Zhao Y, Ran X, Song Y, Liua CJ. Cytochrome b5 is an obligate electron shuttle protein for syringyl lignin biosynthesis in arabidopsis. Plant Cell. 2019;31:1344-66.

52. DeYoung BJ, Innes RW. Plant NBS-LRR proteins in pathogen sensing and host defense. Nat Immuno. 2006;7:1243-9.

53. Al-Whaibi MH. Plant heat-shock proteins: A mini review. J King Saud Univ - Sci. 2011;23:139-50. 
54. Studer AJ, Gandin A, Kolbe AR, Wang L, Cousins AB, Brutnell TP. A limited role for carbonic anhydrase in C4 photosynthesis as revealed by a ca1ca2 double mutant in maize. Plant Physiol. 2014;165:608-17.

55. Hoagland DR DIA. The Water-Culture Method for Growing Plants without Soil the college of agriculture. Agriculture. 1950;347 2nd edit. https://www.cabdirect.org/cabdirect/abstract/19500302257. Accessed 31 Jul 2019.

56. Bolte S, Talbot C, Boutte Y, Catrice O, Read ND, Satiat-Jeunemaitre B. FM-dyes as experimental probes for dissecting vesicle trafficking in living plant cells. J Microsc. 2004;214:159-73. doi:10.1111/j.0022-2720.2004.01348.x.

57. Mochizuki S, Saitoh K, Minami E, Nishizawa Y. Localization of probe-accessible chitin and characterization of genes encoding chitin-binding domains during rice-Magnaporthe oryzae interactions. J Gen Plant Pathol. 2011;77:163-73.

58. O'Leary BM, Rico A, McCraw S, Fones HN, Preston GM. The infiltration-centrifugation technique for extraction of apoplastic fluid from plant leaves using Phaseolus vulgaris as an example. J Vis Exp. 2014. doi:10.3791/52113.

59. Petersen TN, Brunak S, Von Heijne G, Nielsen H. SignalP 4.0: Discriminating signal peptides from transmembrane regions. Nat Metho. 2011;8:785-6.

60. Emanuelsson O, Brunak S, von Heijne G, Nielsen H. Locating proteins in the cell using TargetP, SignalP and related tools. Nat Protoc. 2007;2:953-71.

61. Horton P, Park K-J, Obayashi T, Fujita N, Harada H, Adams-Collier CJ, et al. WoLF PSORT: protein localization predictor. Nucl Acids Res. 2007;35 Web Server:W585-7. doi:10.1093/nar/gkm259.

62. Emanuelsson $\mathrm{O}$, Nielsen $\mathrm{H}$, Brunak S, Von Heijne G. Predicting subcellular localization of proteins based on their $\mathrm{N}$ terminal amino acid sequence. J Mol Biol. 2000;300:1005-16.

63. Bendtsen JD, Jensen LJ, Blom N, von Heijne G, Brunak S. Feature-based prediction of non-classical and leaderless protein secretion. Protein Eng Des Sel. 2004;17:349-56. doi:10.1093/protein/gzh037.

\section{Figures}




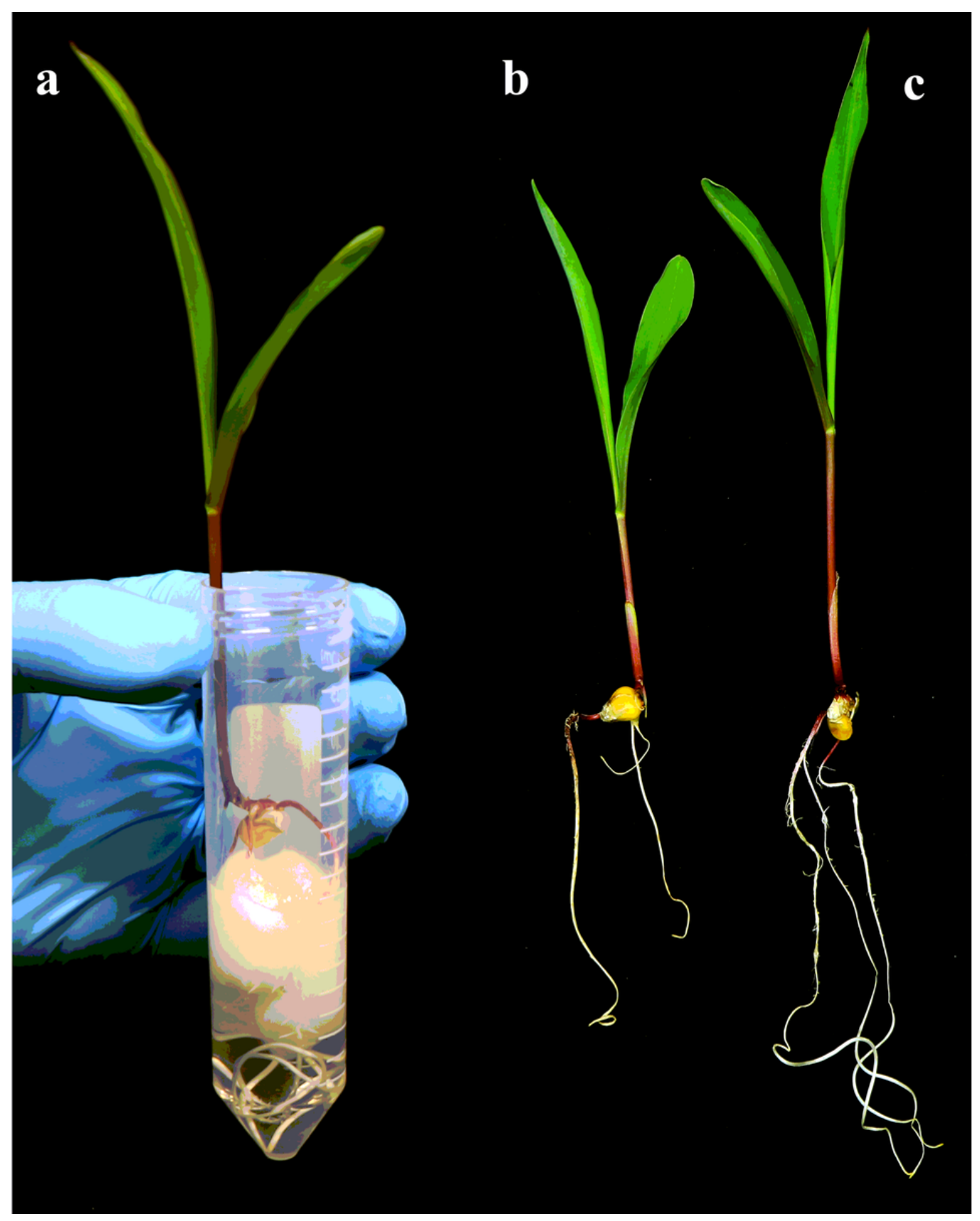

\section{Figure 1}

Interaction of F. verticillioides with maize roots. (A) 7 days old maize seedling growing aseptically under hydroponic conditions. (B) Inoculated seedling showing phenotypical changes in roots system as compared to the (C) Un-inoculated seedling. 

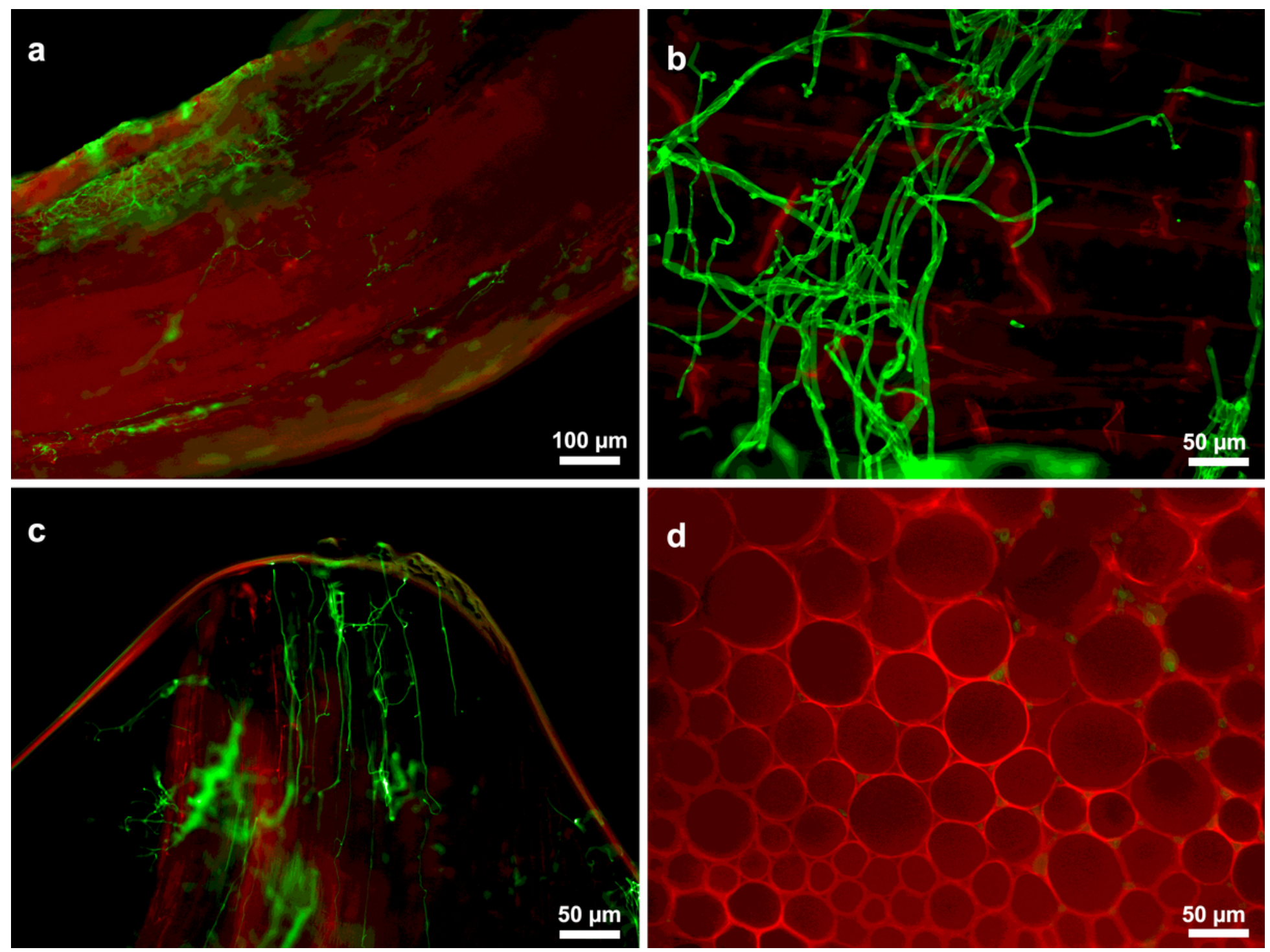

\section{Figure 2}

Colonization pattern of F. verticillioides in maize roots. (A) At 7 days post-inoculation, F. verticillioides can colonize epidermal cells of the primary roots. (B) Close up of the hyphae occupying the epidermal cells of the primary roots and (C) tip of the secondary roots. (D) Intercellular (Apoplast) colonization of cortex cells by F. verticillioides. WGA-Alexa FlourTM 488 (Green Colour), Propidium lodide (PI), and FMTM 4-64 Dye were used for staining of the roots. The plant cell wall was stained with Propidium lodide (PI) (A-C). The plasma membrane was stained with FMTM 4-64 Dye (D), whereas Fungal cells were stained with WGA-Alexa FlourTM 488 (A-D). The Leica DM-2500 Microscope was used to visualize the stained cells and taking photos. 


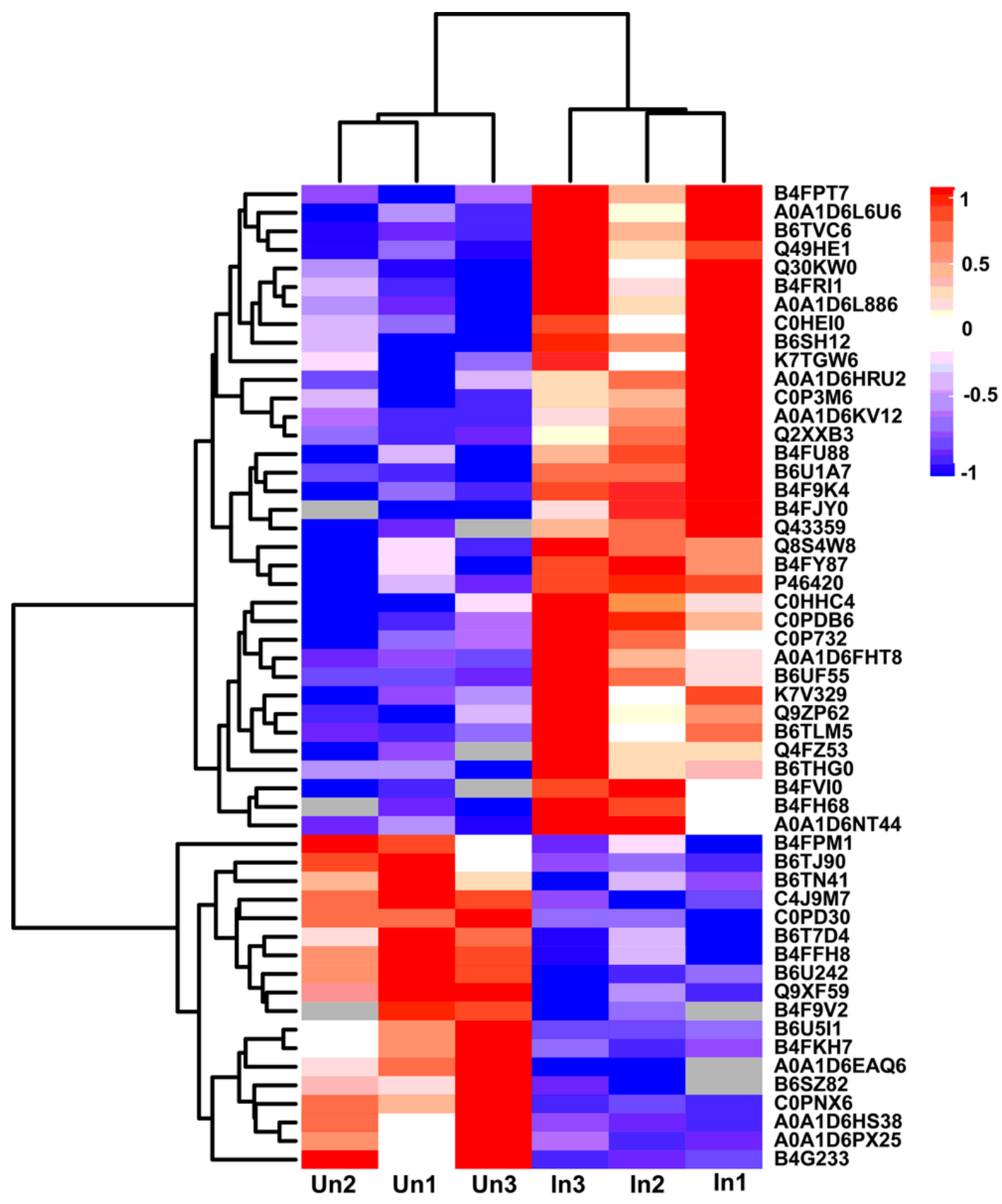

Figure 3

Differentially expressed maize proteins in response to the F. verticillioides infection Heat map showing the differentially expressed (upregulated and down-regulated) maize proteins in response to the F. verticillioides infection after 7 days of inoculation. Bar colours representing the protein expression. Red colour means upregulated expression, and the blue colour means down-regulated expression. Hierarchal clustering was done based on protein expression ( $p$-value $\leq 0.05$ ) between uninoculated (Un1, Un2, Un3) and inoculated (In1, In2, and In3) maize plants. 


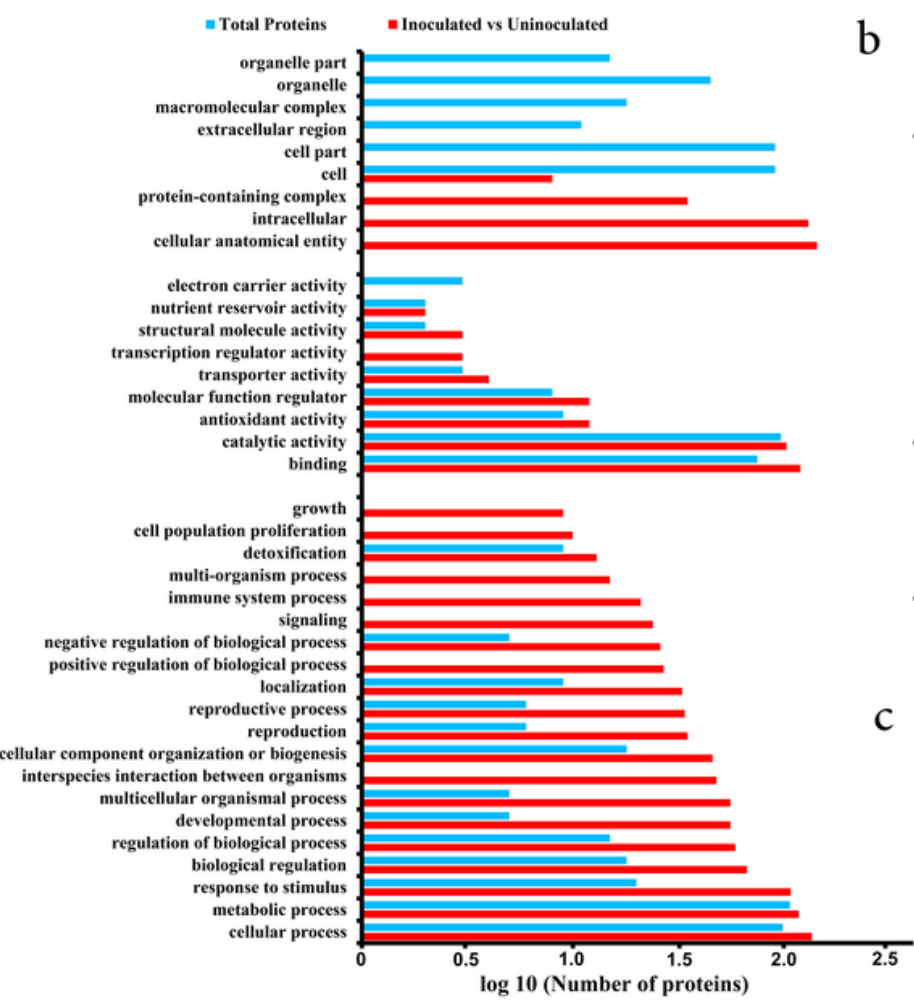

b

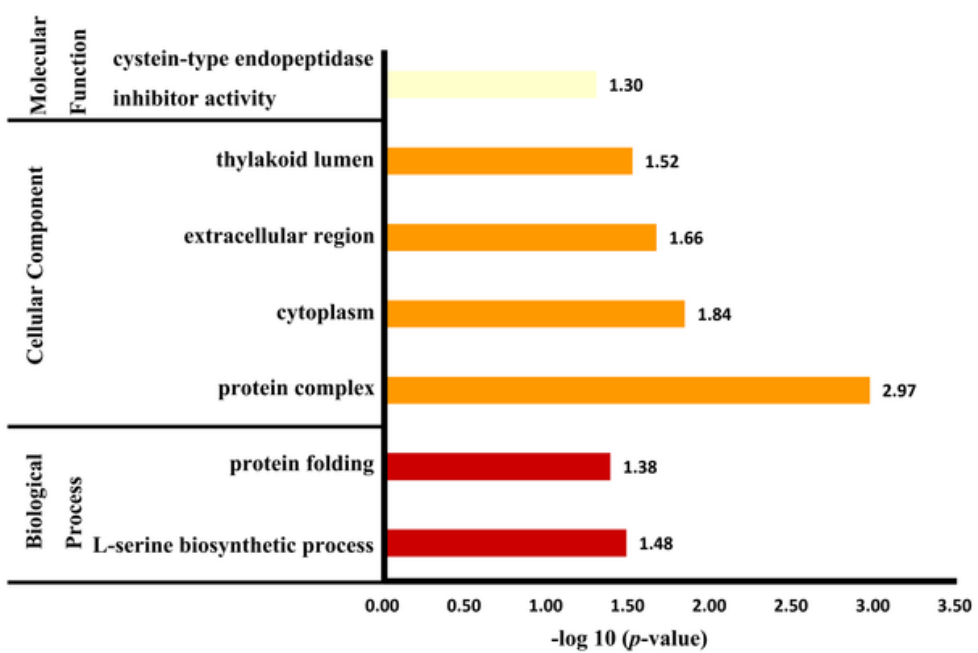

c

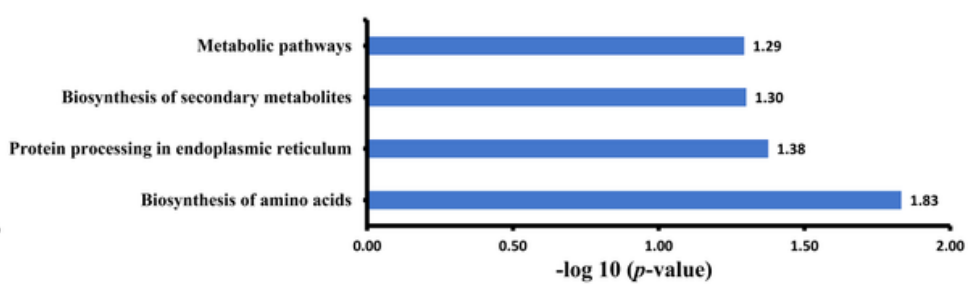

Figure 4

Enrichment analyses of differentially accumulated proteins (DAPs) Gene ontology (GO) and KEGG enriched pathway analysis for the differentially accumulated proteins (DAPs) (a) GO terms for total proteins (all identified) and DAPs. All proteins were classified based on their $\mathrm{GO}$ terms representing the cellular component (CC), molecular function (MF), and biological process (BP). Blue bars representing the total identified proteins, and red bars are representing the DAPs. (b) Enriched GO terms for DAPs during the interaction of maize with F. verticillioides at 7 days post-inoculation. Bar graph showing the enriched GO terms (P-value $\leq 0.05$ ). (c) KEGG enriched pathways for DAPs during the interaction of maize and F. verticillioides at 7 days post-inoculation. Bar graph exhibiting the significant ( $p$-value $\leq 0.05$ ) 


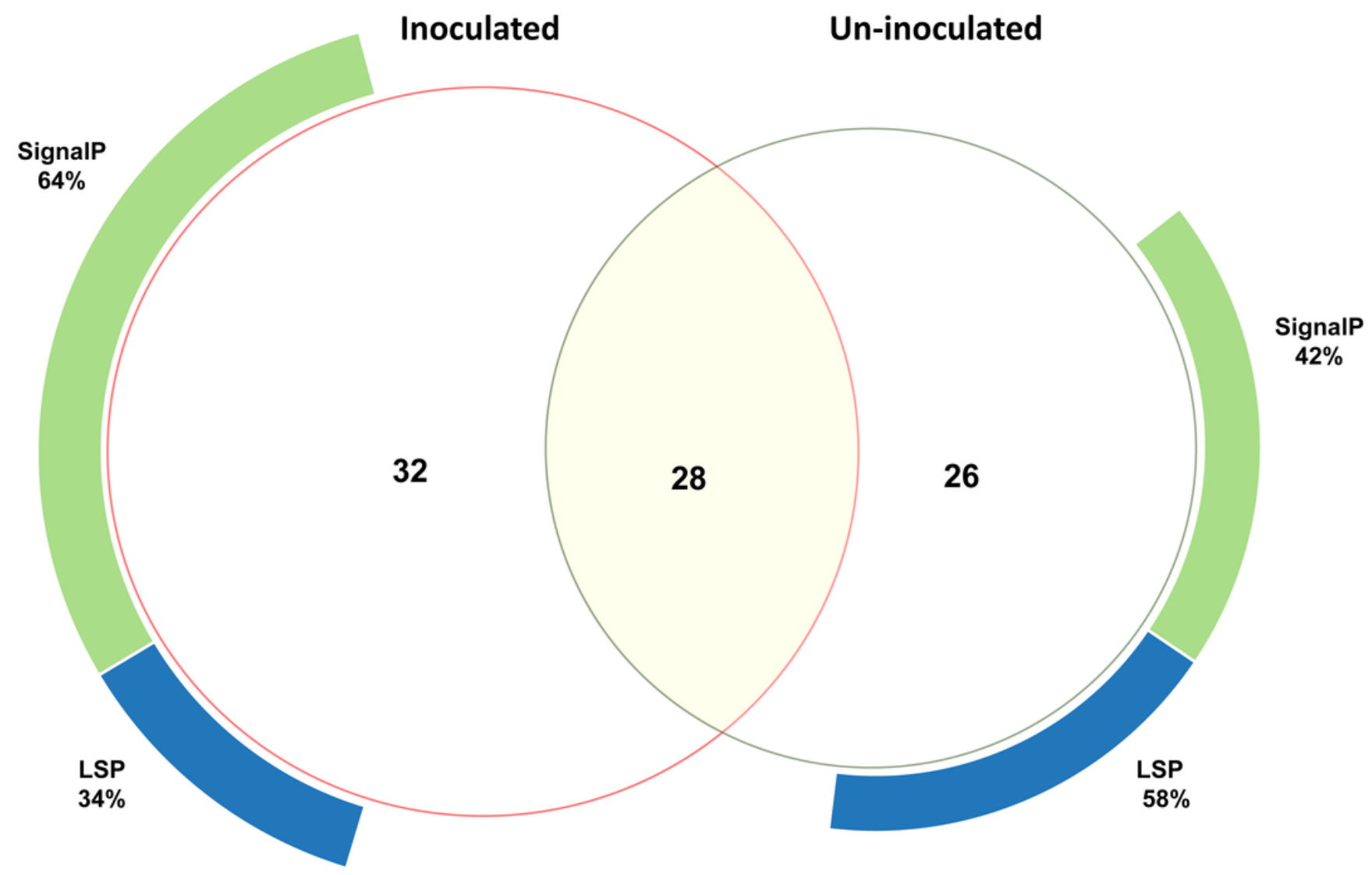

Figure 5

Classical and non-classical secretory proteins of maize Comparison of the proteins secreted by F. verticillioides inoculated and un-inoculated maize plants at 7 days post-inoculation. The presence of the signal peptide was confirmed using the SignalP website. SecretomeP was used to identify the unconventionally secreted or leaderless secreted proteins (LSPs). 
a

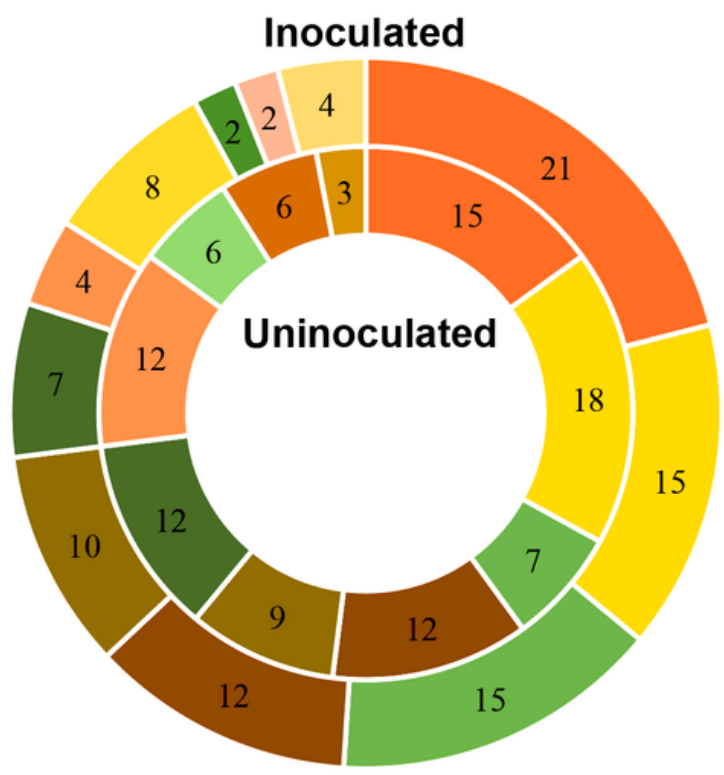

b

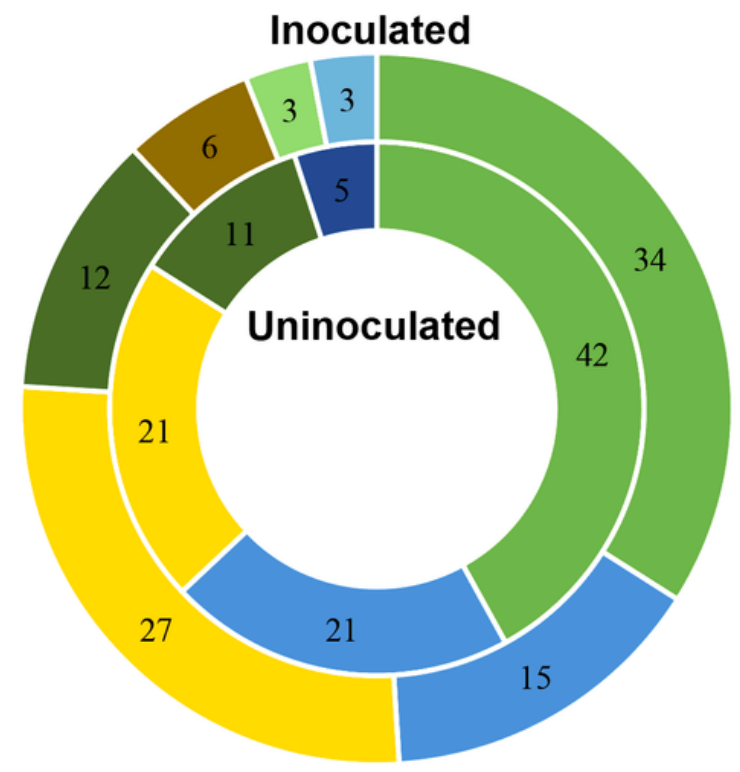

- Organic Substances Metabolic Process

- Cellular Metabolic Process

- Catabolic Process

- Response to Stress

- Nitrogen Compound Metabolic Process

- Small Molecules Metabolic Process

- Biological Regulation

- Carbohydrarate Metabolic Process

- Systemic Acquired Resistance

- Amino Acid Metabolism

- L-Serine Biosythesis

- Protein Complex Oligomerization

- Response to Other Organism

- Organic Substances Biosynthesis
- lon Binding

- Oxidoreductase Activity

Hydrolase activity

- Antioxident Activity

- Transmembrane Transporter Activity

- Transferase Activity

* Structural consituent of Ribosomes

- Enzyme Regulator Activity

Figure 6

Classification of secretory proteins based on their function Functional classification of secreted proteins from maize plants at 7 days interaction with F. verticillioides (a) biological process (BP), (b) molecular function (MF). Score distribution is represented as the percentage of each group inside each slice. 


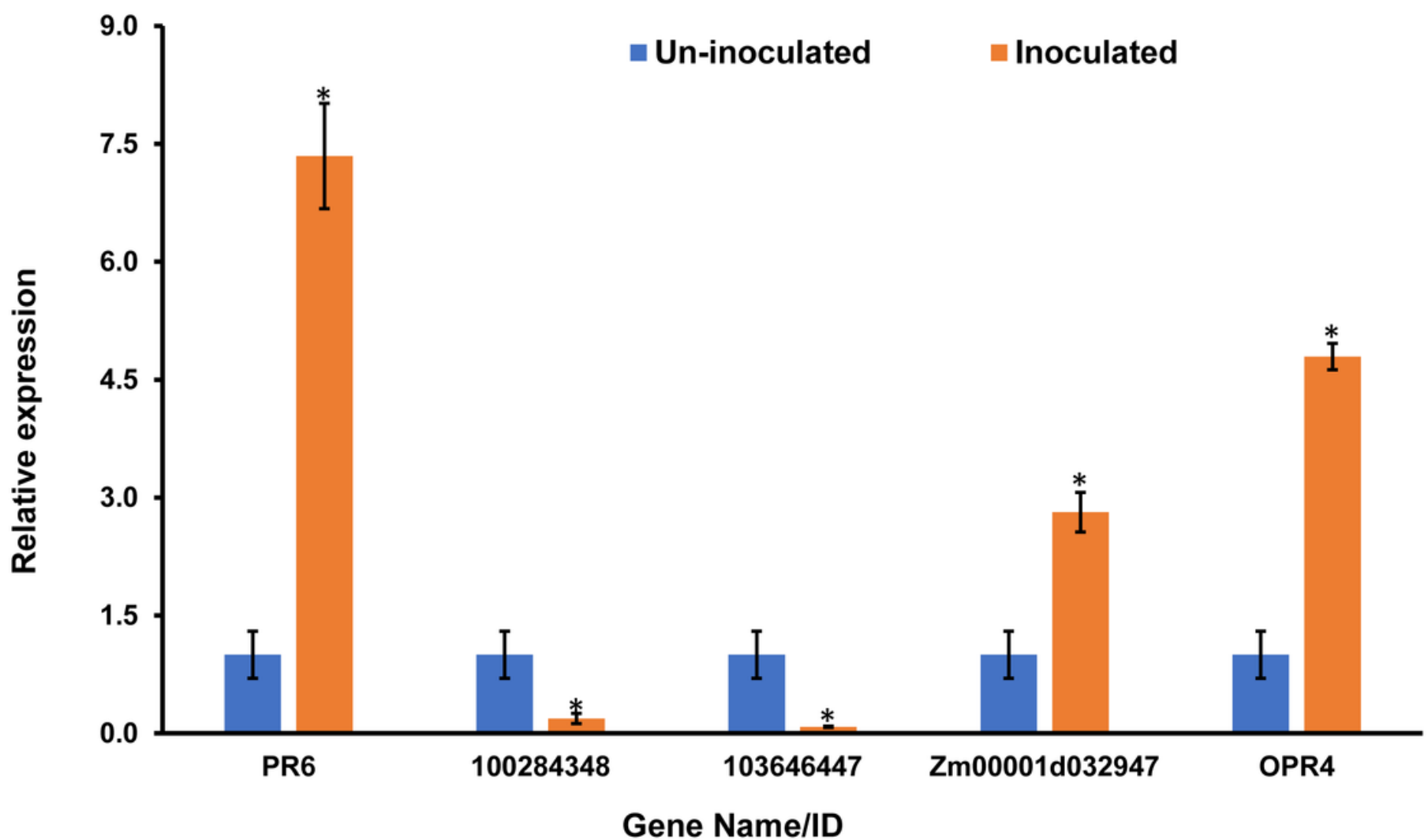

Figure 7

Validation of the results through RT-PCR Reverse transcription-quantitative PCR (RT-qPCR) analysis for the expression of several genes during maize and $F$. verticillioides interaction at 7 days post-inoculation. Actin was used as the internal control in the reaction. Asterisks $\left.{ }^{*}\right)$ indicate significantly different results. ( $p$-value $\leq 0.05$ ).

\section{Supplementary Files}

This is a list of supplementary files associated with this preprint. Click to download.

- AdditionalFileS4.xlsx

- AdditionalFileS3.xlsx

- AdditionalFileS2.xlsx

- AdditionalFileS1.xlsx 